\title{
Perceived Improvements of Quality of Life (QoL) among Patients with Idiopathic Pulmonary Fibrosis (IPF) in Response to a 6-Week Rehabilitation Program
}

\author{
Sameera Peumal Senanayake1,2, Rathugamage Sithija Priyankara Fernando², \\ Heeraluge Erandie Hasini Perera², Ridmi Shashiprabha Maddumage', \\ Athuraliya Gamacharige Kasuni Neranja², \\ Kathaluwa Liyana Kankanamge Tharini Dilanka Sandharenu² \\ ${ }^{1}$ Faculty of Allied Health Sciences, General Sir John Kotelawala Defence University, Werahara, Sri Lanka \\ ${ }^{2}$ School of Sports Sciences, Swansea University, Wales, United Kingdom \\ Email: sp.senanayake@kdu.ac.lk, sithijapriyankara@gmail.com, erandie.perera@gmail.com, \\ ridmimaddumage@gmail.com, kasuni.athuraliya@gmail.com, tharanisandharenu@gmail.com
}

How to cite this paper: Senanayake, S.P., Fernando, R.S.P., Perera, H.E.H., Maddumage, R.S., Neranja, A.G.K. and Sandharenu, K.L.K.T.D. (2021) Perceived Improvements of Quality of Life (QoL) among Patients with Idiopathic Pulmonary Fibrosis (IPF) in Response to a 6-Week Rehabilitation Program. Open Journal of Respiratory Diseases, 11, 27-36.

https://doi.org/10.4236/ojrd.2021.112003

Received: February 12, 2021

Accepted: March 9, 2021

Published: March 12, 2021

Copyright $\odot 2021$ by author(s) and Scientific Research Publishing Inc. This work is licensed under the Creative Commons Attribution International License (CC BY 4.0).

http://creativecommons.org/licenses/by/4.0/ (c) (i) Open Access

\begin{abstract}
Idiopathic pulmonary fibrosis (IPF) is a chronic, life-limiting with an average life expectancy of 05 years following the onset of the disease, with no curative treatments. These patients need palliative care and rehabilitation is one of the methods that can be used to improve quality of life (QoL) among these patients. Yet the research conducted to assess benefits of pulmonary rehabilitation (PR) in terms of improving physical activity and QoL in IPF patients remains limited. Hence this study aims to evaluate the effect of a bespoke pulmonary rehabilitation programme, on the physical, physiological and psychological parameters and improvements of QoL among IPF patients. Eleven (11) subjects with IPF received 6 weeks of pulmonary rehabilitation. An interviewer administered quality of life questionnaire, six-minute walking test (6MWT), Incremental bicycle exercise tests were performed, and cardiac and respiratory parameters were assessed pre- and post-rehabilitation. The 6MWT was significantly increased following training (Pre $312.55 \pm 89.99$; Post, $380.73 \pm 59.60)$. A significant improvement was observed in overall QoL $(2.226 \pm 0.026)$, dyspnoea $(-0.455 \pm 0.004)$ anxiety $(-2.070 \pm 0.038)$, depression $(-2.217 \pm 0.027)$ scores. No significant changes were found in the $\mathrm{VO}_{2}$ max and other cardiopulmonary parameters, while non-significant improvement was seen in $\mathrm{SpO}_{2}$ at peak exercise from 85.8 - 86.5. Bespoke pulmonary
\end{abstract}


rehabilitation program is beneficial in short term improvement of the functional exercise capacity, dyspnoea and QoL among IPF patients.

\section{Keywords}

IPF, 6MWT, Pulmonary Rehabilitation, QoL, Oxygen Uptake, $\mathrm{VO}_{2}$

\section{Introduction}

Idiopathic Pulmonary Fibrosis (IPF) is a chronic, progressive, and life-threatening condition of unknown cause and the commonest of the Idiopathic Interstitial Pneumonia. In the UK, IPF has an annual incidence of approximately 4.6 per 10,000 and is increasing by $5 \%$ per annum [1].

The histological pattern of IPF is characterised by the deposition of excess collagen and other molecules of the extracellular matrix within the alveolar interstitium, together with a modest inflammatory cell infiltrate [2]. This pathological process results in a gradual loss of functioning alveolar units and a decline in pulmonary function. Consequently, people with IPF develop progressive breathlessness and eventually die from respiratory failure. Whilst new therapies which slow the decline in lung function have recently become available, there is still no cure for IPF which has a median survival of three years although the range is wide; some patients follow a slowly declining trajectory over many years whilst others may have a rapidly progressive course [3]. The majority of patients will therefore require supportive care at some point in the course of their disease and national guidelines recommend that oxygen therapy, pulmonary rehabilitation and palliative care should be offered when appropriate [4].

Pulmonary rehabilitation (PR) programmes are of proven value in the management of patients with Chronic Obstructive Pulmonary Disorder (COPD) in whom they improve exercise performance and quality of life (QoL) [5]. However, the benefit of such programmes in terms of improving exercise performance and QoL in people with IPF is less clear. Hence the aim of this study was to evaluate the effects of a PR programme by evaluating physical and physiological parameters and preserved QoL following rehabilitation. Specifically, we evaluated the six-minute walk test (6 MWT), Physiological parameters pertaining to Cardiovascular (heart rate, Blood pressure, Oxygen saturation) and the Respiratory systems (Maximum oxygen uptake, $\mathrm{VO}_{2}$ and oxygen saturation) of the body.

\subsection{Study Setting}

The study assessed a bespoke pulmonary rehabilitation programme for people with IPF, in collaboration with clinical respiratory staff at Morriston Hospital, Swansea, UK. Patients undertaking PR were assessed before and after the completion of the programme, with quantification of cardiac and respiratory variables as markers of physiological function. Quality of life assessments was also 
performed at the same time points via interviewer administered questionnaire. The following research questions will be addressed:

\subsection{Amis and Objectives}

1) Is bespoke pulmonary rehabilitation effective at improving physical function in people with IPF?

2) What is the effect of pulmonary rehabilitation on the 6 MWT.

3) How does pulmonary rehabilitation influence cardiac and respiratory physiology in people with IPF?

4) Does bespoke pulmonary rehabilitation result in improved quality of life in these patients?

\section{Methods}

\subsection{Study Population}

Ethical approval was taken from A-STEM research group, Faculty of Engineering, Swansea University (22.05.2016), followed by the approval of South West Wales Research Ethics Committee, UK (11.10.2016). The study was performed in accordance with the Declaration of Helsinki. Patients who were diagnosed with IPF who fulfilled the 2011 American Thoracic Society and European Respiratory Society guidelines for diagnosis [6], attending the respiratory clinic at Moriston Hospital were invited to participate in the study. A clinical assessment was performed on all potential participants, and their medical histories were reviewed.

\subsection{Inclusion and Exclusion Criteria}

Patients attending the Interstitial Lung Disease Clinic at Moriston Hospital, Swansea, who had been diagnosed with IPF by a Multi-Disciplinary Team, according to the American Thoracic Society (ATS) and European Respiratory Society (ERS) guidelines were eligible to participate. Patients were not eligible to participate if: they had experienced a respiratory infection within the previous two months; had known coronary or valvular heart disease; had any other serious co-morbid condition (e.g. emphysema, uncontrolled diabetes, renal disease); had significant hypoxia (oxygen saturation below $85 \%$ ) when breathing air and undergoing conventional screening for a pulmonary rehabilitation programme; had musculoskeletal problems that would make it impossible to exercise; were current smokers.

\subsection{Experiment Protocol}

The Participants were given information about the particulars of the study and the written consent was obtained after answering any question they had on the study. This was followed by registration of the patients for the PR programme. Once the registration was completed, they completed interviewer administered QoL questionnaire immediately before and immediately after the completion of 
the rehabilitation programme. The questionnaire consisted of two parts: the European Quality of Life-5 Dimensions (EQ5D) questionnaires developed by the EuroQol Group [7] and the Hospital Anxiety and Depression Score (HADS) [8].

This was followed by a baseline physiological assessment. The participants were asked not to consuming alcohol and caffeine 24 hours and 6 hours respectively before the test. To maintain consistency all tests were conducted on the same time of the day \pm 1 hour.

On day one, the participants undertook a 6 MWT to determine their functional (walking) capacity), in line with the ATS guidelines [9]. On the second day, they were asked to complete an incremental bicycle exercise test on a stationary bicycle (ergometer) (VIAsprint ${ }^{\mathrm{tm}}$ 150P Ergometer, Vyaire Medical, IL, USA) in accordance with methods described by McNarry et al. [10], Arena et al. [11] and Senanayake et al. [12]. Participants first completed three minutes of warmup, followed by an increased rate of resistance at a rate of $10-15 \mathrm{~W} \cdot \mathrm{min}^{-1}$, depending on the individual's age-predicted maximum workload. They were asked to always maintain a cadence of $55-60 \mathrm{rpm}$ and to continue cycling until they reached their limit of exercise tolerance. Throughout the test, patients were asked to breathe through a facemask which continuously sampled the inspired and expired air using a tube flow sensor (MCD Medgraphics Ultima CardiO2; MGC Diagnostics, MN, USA). Breath-by-breath data were analysed using the Breeze software package (Version 6.4.1, Medical Graphics, MN, USA). Aerobic threshold (AT) was identified by using methods used by Castro et al. and Senanayake et al. [13] [14]. Blood oxygen saturation was continuously monitored (Nonin Model 7500, Plymouth, MN, USA).

\subsection{Data Analysis}

The One-Sample Kolomogorov-Smirnov Test was used to test the null hypothesis with the assumption that data obeyed a Normal distribution. If this assumption was violated, then the influence of the rehabilitation intervention on each variable was assessed using Wilcoxon Signed Rank tests. One-sample Kolmogorov-Smirnov tests showed that none of the quantified variables were Normally distributed. Statistical significance was assumed at the $\mathrm{p}<0.05$ level.

\section{Discussion}

This research aimed to determine if bespoke pulmonary rehabilitation programme had any impact on the cardiopulmonary response and its effects on exercise and functional capacity of IPF patients using the $6 \mathrm{MWT}$ as a benchmark. This test evaluates the integrated response of all the systems involved during exercise, especially the pulmonary and the cardiovascular system [9]. The results of our study showed that the level of dyspnoea was reduced while exercise capacity and the QoL of the patients significantly improved after the completion of the rehabilitation programme.

Dyspnoea is identified as a major symptom of IPF which results in difficulties 
in conducting the daily physical activity, contributes to exercise intolerance, panic attacks and an overall reduction in QoL [15] Prevention of dyspnoea is considered a key goal in the management of IPF [15]. A similar study conducted by Nishiyama et al. and Ozalevli et al. [16] [17] demonstrated the possibility of increasing exercise capacity, by lowering dyspnoea perception without changing lung function, leading to an improvement in QoL. This comes in par with the findings of our study which indicated a significant improvement in dyspnoea perception and exercise capacity following the PR programme, where the group average 6 MWT distance improved from 312 meters (pre rehabilitation) to 380 meters (post rehabilitation), while increasing the average group laps from 30 (pre) to 37 (post) laps (Table 1). Du Bios et al. established a minimal clinical important difference (MCID) for 6 MWD as $24-45 \mathrm{~m}$ among patients with IPF [18]. The significant improvement found in our study goes above this MCID threshold indicating the clinically meaningful effect of our PR programme (Figure 1). These findings are in accord with the studies done by Vainshelboim et al. [19], Holland et al. [20] and Nishiyama et al. [21], where there was an improvement on exercise capacity and a reduction in dyspnoea leading to improved perceived QoL.

A key characteristic of IPF is the impairment of lung tissue due to fibrosis leading to a gradual loss of oxygen uptake leading to a reduction in $\mathrm{O}_{2}$ saturation $\left(\mathrm{SpO}_{2}\right)$. This occurs mainly due to the alveolar ventilation-perfusion mismatching (VA/Q), oxygen diffusion limitations and low mixed venous oxygen content [20]. However, our results showed an increase in $\mathrm{SpO}_{2}$ at peak exercise from 85.8 - 86.5 (Table 2). Although statistically not significant this is an indication of improvement in oxygen uptake and delivery and we predict this will become statistically significant with an increase in the study population. Studies conducted by both Nishiyama et al. [21] and Ozalevli et al. [17] revealed that PR has no effect on respiratory functions and the gas exchange in IPF. Hence this increase

Table 1. Values for six-minute walk distance (6 MWD) and maximum/minimum ranges for Oxygen saturation $\left(\mathrm{SpO}_{2}\right)$, Heart rate and blood pressure before pulmonary rehabilitation (PR) and after PR.

\begin{tabular}{cccc}
\hline Variable & $\mathrm{N}$ & Pre & Post \\
\hline Weight $(\mathrm{kg})$ & 11 & $88.08 \pm 16.41$ & $86.64 \pm 15.59$ \\
BMI $\left(\mathrm{kg} / \mathrm{m}^{2}\right)$ & 11 & $30.63 \pm 5.11$ & $30.18 \pm 4.82$ \\
6 Min Walk Test $(\mathrm{m})$ & 11 & $312.55 \pm 89.99$ & $380.73 \pm 59.60$ \\
No. of Laps & 11 & $30.91 \pm 8.83$ & $37.91 \pm 5.99$ \\
$\mathrm{SpO}_{2}(\%)$ Min & 11 & $85.82 \pm 5.71$ & $86.55 \pm 5.24$ \\
Max & 11 & $92.55 \pm 3.96$ & $92.10 \pm 2.74$ \\
Heart Rate (BPM) Min & 11 & $81.55 \pm 13.66$ & $88.45 \pm 16.92$ \\
Max & 11 & $105.18 \pm 22.91$ & $118.45 \pm 26.18$ \\
\hline
\end{tabular}

Values are presented as means $\pm \mathrm{SD}^{\star} \mathrm{p}<0.05,{ }^{* *} \mathrm{p}<0.01$ 
Table 2. Cardiopulmonary indices were calculated pre- and post-intervention. Ve; Minute ventilation measured in breaths per minute, $\mathrm{VO}_{2}$ Max; Maximum volume of uptake of oxygen measured (averaging the highest $\mathrm{VO}_{2}$ values obtained in the last 10 seconds before the limit of exercise was reached), $\mathrm{VO}_{2} / \mathrm{HR}$; the ratio of volume of oxygen uptake against the heart rate, $\mathrm{Ve} / \mathrm{VCO}_{2}$ Ventilatory equivalent for carbon dioxide and $\mathrm{Ve} / \mathrm{VO}_{2}$; Ventilatory equivalent for oxygen.

\begin{tabular}{cccc}
\hline Variable & $\mathrm{N}$ & Pre & Post \\
\hline $\mathrm{V}_{\mathrm{E}}(\mathrm{BPM})$ & 11 & $63.13 \pm 18.69$ & $59.67 \pm 18.51$ \\
$\mathrm{VO}_{2} \mathrm{Max}(\mathrm{ml} / \mathrm{kg} / \mathrm{min})$ & 11 & $15.99 \pm 4.79$ & $14.80 \pm 4.88$ \\
$\mathrm{VO}_{2} / \mathrm{HR}$ & 11 & $11.45 \pm 2.07$ & $10.55 \pm 1.57$ \\
$\mathrm{~V}_{\mathrm{E}} / \mathrm{VO}_{2}$ & 11 & $46.00 \pm 5.87$ & $47.18 \pm 6.77$ \\
$\mathrm{~V}_{\mathrm{E}} / \mathrm{VCO}_{2}$ & 11 & $44.00 \pm 4.80$ & $45.27 \pm 7.56$ \\
\hline
\end{tabular}

Values are presented as means $\pm \mathrm{SD}{ }^{*} \mathrm{p}<0.05,{ }^{* *} \mathrm{p}<0.01$.

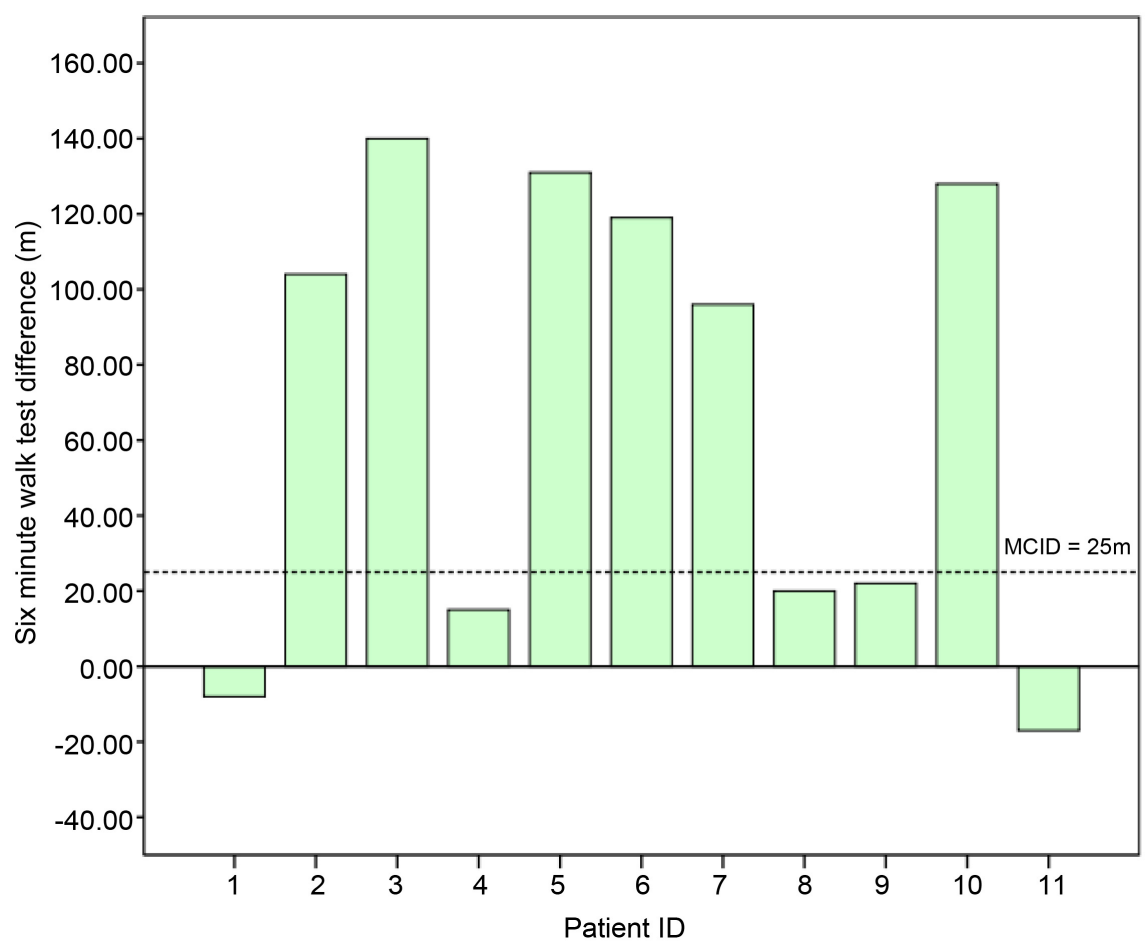

Figure 1. Individual changes $6 \mathrm{MWT}$ after the 6-week pulmonary rehabilitation programme.

seen in our study could be due to improvements in the cardiopulmonary response of these individuals. This is backed by the observations we made in the HR of these individuals following PR, where maximum HR was relatively unchanged (slightly lower in some individual cases) post rehabilitation indicating an improvement in the cardiac function of these patients (Table 1). Ozalevli et al. [17] suggest that the improvements in the oxygen saturation might be an important functional parameter contributing to the increase in 6 MWT.

As shown in Table 2, there were no significant changes in the $\mathrm{VO}_{2}$ max and other cardiopulmonary parameters post rehabilitation indicating they had no 
effect on the improvements in dyspnoea and 6 MWT. Nishiyama et al. [22] and Spirit et al. [23] also stated that peripheral muscle weakness is a predictive factor in exercise intolerance. Peripheral muscle adaptations due to a reduction in weight and BMI following rehabilitation could be another factor contributing to the improvements in the $6 \mathrm{MWT}$ and increased perceived QoL of these patients.

IPF causes a significant psychological impact on diseased individuals. This ranges from depression, anxiety, Trauma and stigma [24]. Studies conducted by Senanayake et al. and Akhtar et al. [25] reported that most of the IPF patients exhibit depression and anxiety. Following rehabilitation both the overall HAD depression score and HAD anxiety scores improved greatly (Table 3). The same trend is seen in sleep and relaxation scores, contributing to the improved preserved QoL.

Jastrzebski et al. [26], Ong et al. [27] says, improving the QoL of IPF patients is considered as one of the major goals in IPF management. Significant improvements in Total QoL following rehabilitation were found in our study supporting the evidence of the effectiveness of our programme. Improvements were observed in all the categories of the QoL questioners. Furthermore, non-significant improvements of sleep and relaxation scores were observed in patients individually suggesting that the PR programme has some positive effect on better sleep leading to a better QoL (Table 4).

\section{Limitations}

When considering the results reported here we must be mindful of potential confounders relating to both the IPF patient population and also our study design. Whilst we consider our sample of 15 patients to be representative of people with IPF, one limitation of this study is the relatively small number of participants which reduced the statistical power of our analyses. We excluded patients who had co-morbid conditions that might influence respiratory and cardiac functions. However, we were also mindful of the potential influence of too strict

Table 3. Key results extracted from QoL questioners "EQ5D and HADS" pre- and post-PR, where MRC dyspnoea scale refers to breathlessness.

\begin{tabular}{cccc}
\hline Variable & $\mathrm{N}$ & Pre & Post \\
\hline MRC dyspnoea scale (0-4) & 11 & $2.91 \pm 0.94^{\star *}$ & $2.45 \pm 0.69^{* *}$ \\
HAD Depression & 11 & $4.09 \pm 3.15$ & $3.27 \pm 3.10^{\star *}$ \\
HAD Anxiety & 11 & $6.09 \pm 3.81$ & $4.45 \pm 3.33$ \\
QoL Total & 8 & $400.0 \pm 103.12$ & $445.0 \pm 72.16^{* *}$ \\
Social activity score & 8 & $80.63 \pm 21.78^{\star}$ & $89.38 \pm 19.72^{\star *}$ \\
Leisure Activity score & 8 & $77.5 \pm 22.99$ & $90.0 \pm 28.28^{\star *}$ \\
Personal Care & 8 & $85.0 \pm 18.32^{*}$ & $90.0 \pm 15.12^{\star *}$ \\
Sleep and Relaxation & 8 & $73.75 \pm 27.22$ & $85.63 \pm 16.35^{*}$ \\
Roles and Routine & 8 & $83.13 \pm 27.38^{*}$ & $90.0 \pm 21.38^{\star *}$ \\
\hline
\end{tabular}

Values are presented as means $\pm \mathrm{SD}^{\star} \mathrm{p}<0.05,{ }^{* *} \mathrm{p}<0.01$ 
Table 4. Differences between the selected parameters before and after six weeks of the PR programme.

\begin{tabular}{ccc}
\hline & Difference $(95 \% \mathrm{CI})$ & Statistical Significance \\
\hline 6 Min Walk Test & 68.182 & 0.004 \\
MRC (1-4) & -0.455 & 0.016 \\
HAD Depression $(0-21)$ & -2.070 & 0.038 \\
HAD Anxiety $(0-21)$ & -2.217 & 0.027 \\
QoL Total & 2.226 & 0.026 \\
Social activity score & 8.75 & 0.262 \\
Leisure Activity score & 12.50 & 0.147 \\
Personal Care & 5.00 & 0.155 \\
Sleep and Relaxation & 11.88 & 0.074 \\
Roles and Routine & 6.87 & 0.102 \\
Weight $(\mathrm{kg})$ & -1.400 & 0.161 \\
BMI kg/m ${ }^{2}$ & -1.122 & 0.262 \\
VO ${ }_{2}$ Max & -1.735 & 0.083 \\
\hline
\end{tabular}

a set of exclusion criteria on both recruitment and the applicability of our results to the wider IPF population.

\section{Conclusions and Recommendations}

The results of our study indicate the bespoke PR program is of benefit in short term improvement of the functional exercise capacity, dyspnoea and QoL among IPF patients. We believe with the increase in the number of participants will result in statistically significant results in other categories of the QoL questioners. Hence, we recommend using this study as a pilot study for a larger study in the future and to measure the sustainability of these improvements with a follow-up.

\section{Conflicts of Interest}

The authors declare no conflicts of interest regarding the publication of this paper.

\section{References}

[1] Gribbin, J., Hubbard, R.B., Le Jeune, I., Smith, C.J., West, J. and Tata, L.J. (2006) Incidence and Mortality of Idiopathic Pulmonary Fibrosis and Sarcoidosis in the UK. Thorax, 61, 980-985. https://doi.org/10.1136/thx.2006.062836

[2] Navaratnam, V., Fogarty, A.W., Glendening, R., McKeever, T. and Hubbard, R.B. (2013) The Increasing Secondary Care Burden of Idiopathic Pulmonary Fibrosis: Hospital Admission Trends in England from 1998 to 2010. Chest, 143, 1078-1084. https://doi.org/10.1378/chest.12-0803

[3] National Institute for Health and Care Excellence (Great Britain) (2017) Idiopathic Pulmonary Fibrosis in Adults: Diagnosis and Management. National Institute for Health and Care Excellence (NICE). 
[4] Bolton, C.E., Bevan-Smith, E.F., et al. (2013) British Thoracic Society Guideline on Pulmonary Rehabilitation in Adults: Accredited by NICE. Thorax, 68, ii1-ii30. https://doi.org/10.1136/thoraxjnl-2013-203808

[5] Duck, A. (2015) Recognising and Managing Patients with Interstitial Lung Disease. Journal of Community Nursing, 29, 48-52.

[6] Raghu, G., Collard, H.R., Egan, J.J., Martinez, F.J., Behr, J., Brown, K.K., et al. (2011) An Official ATS/ERS/JRS/ALAT Statement: Idiopathic Pulmonary Fibrosis: Evidence-Based Guidelines for Diagnosis and Management. American Journal of Respiratory and Critical Care Medicine, 183, 788. https://doi.org/10.1164/rccm.2009-040GL

[7] Herdman, M., Gudex, C., Lloyd, A., et al. (2011) Development and Preliminary Testing of the New Five-Level Version of EQ-5D (EQ-5D-5L). Quality of Life Research, 20, 1727-1736. https://doi.org/10.1007/s11136-011-9903-x

[8] Zigmond, A.S. and Snaith, R.P. (1983) The Hospital Anxiety and Depression Scale. Acta Psychiatrica Scandinavica, 67, 361-370. https://doi.org/10.1111/j.1600-0447.1983.tb09716.x

[9] Torrey, B. (2002) ATS Guidelines for the Six-Minute Walk Test. (American Thoracic Society Committee on Proficiency Standards for Clinical Pulmonary Function Laboratories). American Family Physician, 66, 904.

[10] McNarry, M.A., Harrison, N.K., Withers, T., Chinnappa, N. and Lewis, M.J. (2017) Pulmonary Oxygen Uptake and Muscle Deoxygenation Kinetics during Heavy Intensity Cycling Exercise in Patients with Emphysema and Idiopathic Pulmonary Fibrosis. BMC Pulmonary Medicine, 17, Article No. 26. https://doi.org/10.1186/s12890-017-0364-Z

[11] Arena, R. and Sietsema, K.E. (2011) Cardiopulmonary Exercise Testing in the Clinical Evaluation of Patients with Heart and Lung Disease. Circulation, 123, 668-680. https://doi.org/10.1161/CIRCULATIONAHA.109.914788

[12] Senanayake, S.P., Harrison, K., Hilldrup, S. and Lewis, M. (2020) Influence of Rehabilitation on Oxygen Uptake Kinetics during High Intensity Exercise in Patients with Idiopathic Pulmonary Fibrosis. Open Journal of Respiratory Diseases, 10, 59-74. https://doi.org/10.4236/ojrd.2020.104007

[13] Castro, R.R., Pedrosa, S., Chabalgoity, F., Sousa, E.B. and Nobrega, A.C. (2010) The Influence of A Fast Ramp Rate on Peak Cardiopulmonary Parameters during Arm Crank Ergometry. Clinical Physiology and Functional Imaging, 30, 420-425. https://doi.org/10.1111/j.1475-097X.2010.00958.x

[14] (2020) Influence of Physical Rehabilitation on Heart Rate Dynamics in Patients with Idiopathic Pulmonary Fibrosis.

[15] Ryerson, C.J., Donesky, D., Pantilat, S.Z. and Collard, H.R. (2012) Dyspnea in Idiopathic Pulmonary Fibrosis: A Systematic Review. Journal of Pain and Symptom Management, 43, 771-782. https://doi.org/10.1016/j.jpainsymman.2011.04.026

[16] Nishiyama, O., Kondoh, Y., Kimura, T., et al. (2008) Effects of Pulmonary Rehabilitation in Patients with Idiopathic Pulmonary Fibrosis. Respirology, 13, 394-399. https://doi.org/10.1111/j.1440-1843.2007.01205.x

[17] Ozalevli, S., Karaali, H.K., Ilgin, D. and Ucan, E.S. (2010) Effect of Home-Based Pulmonary Rehabilitation in Patients with Idiopathic Pulmonary Fibrosis. Multidisciplinary Respiratory Medicine, 5, Article No. 31. https://doi.org/10.1186/2049-6958-5-1-31

[18] du Bois, R.M., Weycker, D., Albera, C., Bradford, W.Z., Costabel, U., Kartashov, A., et al. (2011) Ascertainment of Individual Risk of Mortality for Patients with Idi- 
opathic Pulmonary Fibrosis. American Journal of Respiratory and Critical Care Medicine, 184, 459-466. https://doi.org/10.1164/rccm.201011-1790OC

[19] Vainshelboim, B., Oliveira, J., Fox, B.D., Soreck, Y., Fruchter, O. and Kramer, M.R. (2015) Long-Term Effects of a 12-Week Exercise Training Program on Clinical Outcomes in Idiopathic Pulmonary Fibrosis. Lung, 193, 345-354. https://doi.org/10.1007/s00408-015-9703-0

[20] Holland, A.E., Hill, C.J., Conron, M., Munro, P. and McDonald, C.F. (2008) Short term Improvement in Exercise Capacity and Symptoms Following Exercise Training in Interstitial Lung Disease. Thorax, 63, 549-554.

https://doi.org/10.1136/thx.2007.088070

[21] Nishiyama, O., Kondoh, Y., Kimura, T., Kato, K., Kataoka, K., Ogawa, T., et al. (2008) Effects of Pulmonary Rehabilitation in Patients with Idiopathic Pulmonary Fibrosis. Respirology, 13, 394-399. https://doi.org/10.1111/j.1440-1843.2007.01205.x

[22] Osamu, N., Taniguchi, H., Kondoh, Y., Kimura, T., Ogawa, T., Watanabe, F., et al. (2005) Quadriceps Weakness is Related to Exercise Capacity in Idiopathic Pulmonary Fibrosis. Chest, 127, 2028-2033. https://doi.org/10.1378/chest.127.6.2028

[23] Spruit, M.A., Thomeer, M.J., Gosselink, R., Troosters, T., Kasran, A., Debrock, A., et al. (2005) Skeletal Muscle Weakness in Patients with Sarcoidosis and Its Relationship with Exercise Intolerance and Reduced Health Status. Thorax, 60, 32-38. https://doi.org/10.1136/thx.2004.022244

[24] Sameera, S., Harrison, K., Lewis, M., McNarry, M. and Hudson, J. (2018) Patients' Experiences of Coping with Idiopathic Pulmonary Fibrosis and Their Recommendations for Its Clinical Management. PLoS ONE, 13, e0197660. https://doi.org/10.1371/journal.pone.0197660

[25] Akhtar, A., Mohammad, A. and Robin, S. (2013) Depression in Patients with Idiopathic Pulmonary Fibrosis. Chronic Respiratory Disease, 10, 127-133. https://doi.org/10.1177/1479972313493098

[26] Jastrzebski, D., Gumola, A., Gawlik, R. and Kozielski, J. (2006) Dyspnea and Quality of Life in Patients with Pulmonary Fibrosis after Six Weeks of Respiratory Rehabilitation. Journal of Physiology and Pharmacology, 57, 139-148.

[27] Ong, K.C., Wong, W.P., Jailani, A.R., Sew, S. and Ong, Y.Y. (2001) Effects of A Pulmonary Rehabilitation Programme on Physiologic and Psychosocial Outcomes in Patients with Chronic Respiratory Disorders. Annals of the Academy of Medicine, Singapore, 30, 15-21. 